Review

\title{
Wetting by Liquid Metals-Application in Materials Processing: The Contribution of the Grenoble Group
}

\author{
Nicolas Eustathopoulos \\ SIMAP, University Grenoble Alpes-CNRS, F-38000 Grenoble, France; \\ E-Mail: nikos@simap.grenoble-inp.fr \\ Academic Editor: Enrique Louis
}

Received: 4 February 2015 / Accepted: 1 March 2015 / Published: 10 March 2015

\begin{abstract}
The wettability of ceramics by liquid metals is discussed from both the fundamental point of view and the point of view of applications. The role of interfacial reactions (simple dissolution of the solid in the liquid or formation of a layer of a new compound) is illustrated and analysed. Several results are presented in order to illustrate the role of wettability in materials processing, namely infiltration processing, joining dissimilar materials by brazing and selecting crucibles for crystallising liquid metals and semiconductors. The review includes results obtained during the last 15 years mainly, but not only, by the Grenoble group.
\end{abstract}

Keywords: wetting; reactivity; metals; ceramics; composites; brazing; infiltration; crucible

\section{Introduction}

The intrinsic aptitude of a non-reactive liquid to wet a flat, smooth and chemically homogeneous solid surface is quantified by the value of Young's contact angle $\theta_{\mathrm{Y}}$, a unique characteristic of a solid S-liquid L-vapour V system (Figure 1). $\theta$ y enters into all model equations describing the wetting of liquids on real solid surfaces, i.e., surfaces with a certain roughness and degree of heterogeneity, as well as into equations modelling wetting in reactive liquid-solid systems. Moreover, by measuring $\theta \mathrm{Y}$ and the surface energy (or surface tension) $\sigma_{L V}$ of the liquid Dupré's adhesion energy $W_{\mathrm{a}}$ can be evaluated. This quantity characterises the thermodynamic stability of interfaces between dissimilar materials and is widely used in practice for predicting their potential bonding properties. 


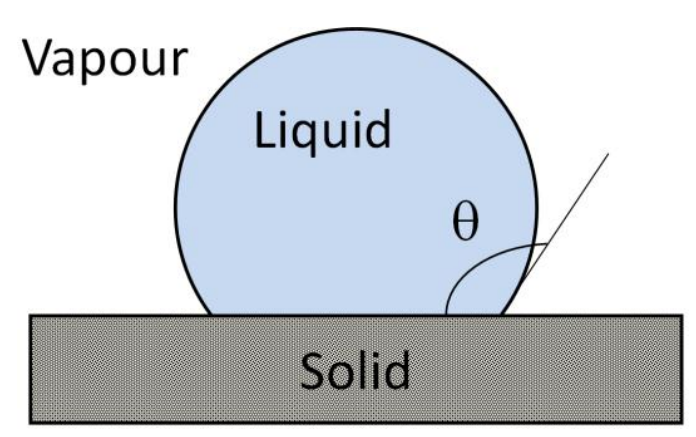

Figure 1. Definition of the equilibrium contact angle $\theta$. For a flat, smooth and chemically homogeneous solid surface, $\theta$ is the Young contact angle $\theta$ y.

During the last decades, significant improvements have been made in the measurement of contact angles of high temperature systems [1]. In this period, wetting studies have benefited from high resolution techniques for characterising the topological and chemical features of surfaces at nanometric scale. Another reason for this improvement has been the use of monocrystalline or vitreous solids to prepare the high-quality surfaces required for Young's contact angle determinations. Over the past 15 years, further improvements have been made as an increasing number of laboratories are now using more sophisticated versions of the sessile drop method (dispensed drop, transferred drop) enabling in situ cleaning of surfaces. Finally, automatic systems for data acquisition and image analysis leading to the simultaneous measurement of contact angle and surface tension have been developed and used widely.

Data on the wetting of ceramics by liquid metals published until the end of the last century have been extensively reviewed in [2]. Another review with special emphasis on alloys used for soldering in microelectronics was published in 2007 [3]. After giving a brief overview of the fundamental equations of wetting and adhesion for both smooth and rough solid surfaces, this article aims to review results obtained during the last 15 years for non-reactive and reactive liquid-solid systems. Although this review focuses on liquid metal/ceramic systems, a limited number of results concerning liquid metal-solid metal systems are also given because they are useful in understanding bonding at $\mathrm{metal} /$ ceramic interfaces. Several experimental results are presented in the paper in order to illustrate the role of wettability in different applications, namely materials' infiltration processing, joining dissimilar materials by brazing and selecting crucibles for solidifying liquid metals and semiconductors. The results are mainly, but not only, from studies performed by the Grenoble group.

\section{Non-Reactive Wetting}

\subsection{Thermodynamics}

The intrinsic contact angle $\theta_{\mathrm{Y}}$ in a non-reactive solid-liquid system is given by the classical equations of Young (Equation (1a)) and Young-Dupré (Equation (1b)):

$$
\cos \theta_{\mathrm{Y}}=\frac{\sigma_{S V}-\sigma_{S L}}{\sigma_{L V}}
$$




$$
\cos \theta_{\mathrm{Y}}=\frac{W_{a}}{\sigma_{L V}}-1
$$

where the quantities $\sigma_{S V}$ and $\sigma_{L V}$ define the surface energy of the solid and liquid, respectively, and $\sigma_{S L}$ the solid/liquid interface energy. $W_{a}$ is the adhesion energy of the system defined as the energy required to separate reversibly a solid and a liquid having a common interface of unit area, creating two free surfaces, one solid-vapour and one liquid-vapour. Therefore, $W_{a}$ is related to the surface energies of the system by $W_{a}=\sigma_{S V}+\sigma_{L V}-\sigma_{S L}$.

According to Equation (1b), the intrinsic contact angle $\theta_{\mathrm{Y}}$ in a non-reactive liquid/solid system results from two types of competing forces: (i) adhesion forces that develop between the liquid and the solid phases, expressed by the quantity of adhesion energy which promotes wetting, and (ii) cohesion forces of the liquid taken into account by the surface energy of the liquid $\sigma_{L V}$ acting in the opposite direction (the cohesion energy of the liquid is equal to $2 \sigma_{L V}$ ).

Usual liquid metals are high surface energy liquids. Their surface energy $\sigma_{L V}$ lies between $0.5 \mathrm{~J} \mathrm{~m}^{-2}$ for low melting point (m.p.) metals such as $\mathrm{Pb}$ and $\mathrm{Sn}$ and $2 \mathrm{~J} \mathrm{~m}^{-2}$ for high m.p. metals such as Fe and Mo [2]. These values, reflecting the high cohesion of metals due to their metallic (i.e., chemical) bonding, are one to two orders of magnitude greater than the surface energies of room temperature liquids in which bonding is achieved by weak, intermolecular interactions (i.e., physical interactions). Then, according to Equation (1b), good wetting (i.e., a contact angle of a few degrees or tens of degrees) of a liquid metal on a solid substrate can be observed if the adhesion energy is close to the cohesion energy of the liquid $2 \sigma L V$. This is possible only if the interfacial bond is strong, i.e., chemical in nature. This condition is fulfilled for liquid metals on solid metals regardless of the miscibility between the liquid and the solid, because in this type of system the interfacial bond is metallic. For instance, good wetting is observed for liquid $\mathrm{Cu}$ on solid Mo despite the absence of any miscibility in this system (Table 1). Liquid metals also wet semiconductors such as $\mathrm{Si}$, Ge or SiC because these solids, that are covalent in the bulk, are metallic in nature near the surface. Finally, liquid metals also wet ceramics such as carbides, nitrides or borides of transition metals because a significant part of the cohesion of these materials is provided by metallic bonds. Among the solids that are not wetted by non-reactive liquid metals are the different forms of carbon, the ionocovalent oxides and the predominantly covalent ceramics with a high band gap like BN. In these non-wetting systems' adhesion is provided by weak van der Waals interactions.

Table 1. Wetting of different types of solids by non-reactive liquid metals at temperatures close to the metal melting point. The contact angle values are from the review [2].

\begin{tabular}{|c|c|c|c|}
\hline Type of substrate & Type of interaction & $\theta$ (degrees) & Examples \\
\hline Solid metals & \multirow{3}{*}{ Strong (chemical) } & \multirow{3}{*}{$\theta<<90^{\circ}$} & $\mathrm{Cu} / \mathrm{Mo}: 10^{\circ}-30^{\circ}$ \\
\hline Semiconductors & & & $\mathrm{Sn} / \mathrm{Ge}: 40^{\circ} ; \mathrm{Si} / \mathrm{SiC}: 35^{\circ}-45^{\circ}$ \\
\hline $\begin{array}{l}\text { Ceramics with a partially } \\
\text { metallic character }\end{array}$ & & & $\mathrm{Cu} / \mathrm{WC}: 20^{\circ} ; \mathrm{Au} / \mathrm{ZrB}_{2}: 25^{\circ}$ \\
\hline Carbon materials & \multirow{2}{*}{ Weak (physical) } & \multirow{2}{*}{$\theta>>90^{\circ}$} & $\mathrm{Au} / \mathrm{C}: 120^{\circ}-135^{\circ}$ \\
\hline Ionocovalent ceramics & & & $\mathrm{Ag} / \mathrm{Al}_{2} \mathrm{O}_{3}, \mathrm{Cu} / \mathrm{SiO}_{2}: 120^{\circ}-140^{\circ} ; \mathrm{Au} / \mathrm{BN}: 135^{\circ}-150^{\circ}$ \\
\hline Ionocovalent oxides & Moderate (chemical) & $\theta \approx 90^{\circ}$ & $(\mathrm{Ag}+\mathrm{O}) / \mathrm{Al}_{2} \mathrm{O}_{3} ; \mathrm{Al} / \mathrm{Al}_{2} \mathrm{O}_{3}$ \\
\hline
\end{tabular}


Between systems with $\theta \mathrm{Y} \gg 90^{\circ}$, corresponding to weak, physical solid-liquid interactions, and systems with $\theta \mathrm{y}<<90^{\circ}$ (strong, chemical interactions), there are some liquid/solid combinations where $\theta_{\mathrm{Y}}$ is in the range $80^{\circ}-100^{\circ}$. These values correspond to an adhesion energy that is $2-2.5$ times higher than the adhesion energy of non-reactive metals on oxides for the same $\sigma_{L V}$ value and reflect the development of moderate interactions of a chemical nature through the interface. In a given metal/oxide couple, when the mole fraction of oxygen dissolved in the metal $x_{o x}$ increases progressively (the source of oxygen being an oxygen-rich gas), the contact angle starts to decrease at a threshold value $\mathrm{x}_{\mathrm{ox}} *$ around $10^{-5}$, by chemisorption of oxygen at the metal/oxide interface [4]. Silver has a very limited affinity for oxygen (silver oxides are in fact unstable), but it can dissolve large amounts of this element resulting in a strong decrease in contact angle on alumina, from a value close to $130^{\circ}$ for pure $\mathrm{Ag}$ to $90^{\circ}$ for $\mathrm{Ag}$ with $\mathrm{x}_{\mathrm{ox}}>10^{-5}$. Contrary to $\mathrm{Ag}$, Al has a very high affinity for oxygen while the solubility of this element in liquid $\mathrm{Al}$ is extremely low. Indeed, the maximum value of $\mathrm{x}_{\mathrm{ox}}$, that is the value of this quantity at the $\mathrm{Al} / \mathrm{Al}_{2} \mathrm{O}_{3}$ interface at $700{ }^{\circ} \mathrm{C}$, is only $10^{-9}$, i.e., several orders of magnitude lower than $\mathrm{x}_{\mathrm{ox}} * \approx 10^{-5}$. Therefore, oxygen chemisorption cannot occur in this case. However, due to its high affinity for oxygen, Al can modify the surface chemistry of the oxide substrate by forming a two-dimensional layer with a lower $\mathrm{O} /$ metal ratio than in the bulk oxide, thus improving wetting.

Equations (1a,b) give the "Young contact angle" $\theta_{\mathrm{Y}}$ or intrinsic contact angle of a liquid on a perfectly smooth and chemically homogeneous solid surface. In most applications, chemical heterogeneities (such as, oxide inclusions on a metallic surface) and the roughness of real solid surfaces lead to deviations in the observed contact angles from $\theta_{\mathrm{y}}$ that can attain several degrees and in some cases tens of degrees [1].

The roughness of the solid surface affects wetting through two different effects: the first is the increase in the actual surface area and the second is pinning of the triple line by sharp defects.

The first effect is expressed by Wenzel's equation:

$$
\cos \theta_{\mathrm{w}}=\mathrm{s}_{\mathrm{r}} \cos \theta_{\mathrm{Y}}
$$

where $\mathrm{Sr}$ denotes the ratio of the actual area to the planar area $(\mathrm{sr}>1)$. According to this equation, if $\theta \mathrm{y}<90^{\circ}, \theta \mathrm{w}$ will be lower than $\theta \mathrm{y}$ and, for $\mathrm{sr}>1 / \cos \theta \mathrm{y}$, perfect wetting will be observed.

Sharp defects can pin the triple line at positions far from stable equilibrium, i.e., at contact angles markedly different from $\theta \mathrm{y}$. This effect is illustrated schematically in Figure 2 where $\theta$ is the macroscopic (or observed) contact angle, $\alpha$ is the inclination of the defect and $\theta \mathrm{Y}$ the microscopic contact angle. This configuration corresponds to a metastable equilibrium state (i.e., to a local minimum of the total energy of the system) where:

$$
\theta=\theta_{\mathrm{Y}}+\alpha
$$

In systems with good wetting $\left(\theta \mathrm{Y}<<90^{\circ}\right)$, the predominant effect of surface roughness is that given by Wenzel's equation. For a $\theta \mathrm{y}$ value close to or higher than $90^{\circ}$, the pinning effect predominates. 


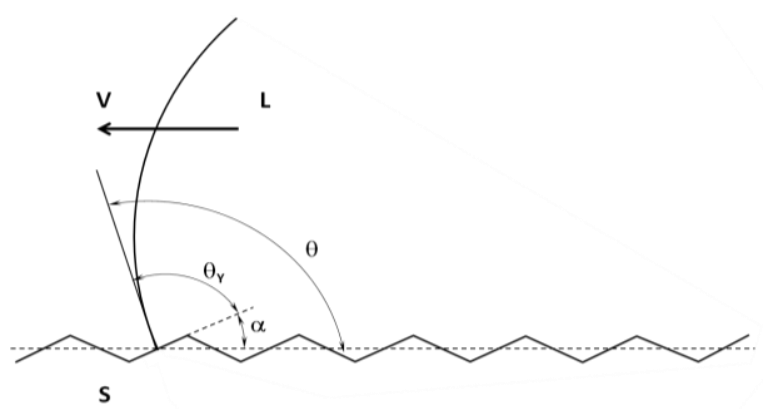

Figure 2. Pinning of the triple line during wetting on a rough surface. Pinning corresponds to a metastable state where the macroscopic contact angle $\theta$ satisfies the relation $\theta=\theta_{\mathrm{Y}}+\alpha$.

When $\theta \mathrm{Y}>>90^{\circ}$, wetting on high-roughness solids leads to the formation of "composite interfaces", partly solid-liquid and partly solid-vapour, (Figure 3a) resulting in contact angles $\theta$ well above $\theta$ y. In this case, even limited stress produced during cooling leads to detachment of the solidified metal from the substrate by a purely adhesive rupture. Finally, when the goal of an experiment is to attain $\theta \mathrm{y}$, solid surfaces with an average roughness less than $100 \mathrm{~nm}$ must be used [1]. The results given in Table 1 have been obtained with this type of substrate.

(a)

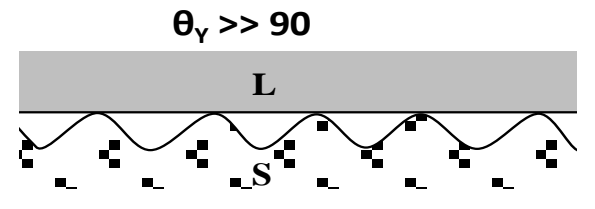

(b)

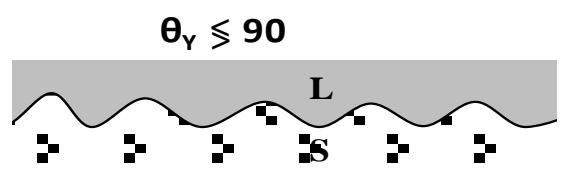

Figure 3. Microscopic configuration at solid/liquid interfaces: (a) For $\theta_{\mathrm{Y}} \gg 90^{\circ}$, at microscopic scale, the liquid contacts the rough surface of the solid only at a few points. During cooling the solidified liquid detaches spontaneously from the solid; (b) For $\theta \mathrm{y}$ values lower than $90^{\circ}$ or higher but close to this value, an intimate contact exists at any point of the interface.

When a solid $\alpha$ contains a dispersion of particles $\beta$, the equilibrium contact angle $\theta_{\mathrm{C}}$ on the heterogeneous surface is given by Cassie's equation:

$$
\cos \theta_{\mathrm{C}}=f_{\alpha} \cos \theta_{\alpha}+f_{\beta} \cos \theta_{\beta}
$$

where $f_{\alpha}$ is the surface area fraction of the matrix. This equation is also applicable to a porous solid taken for the pore $\theta_{\beta}=180^{\circ}$.

\subsection{Kinetics}

As the viscosity of liquid metals and alloys is very low — a few mPas [5] - spreading of this type of liquid is a very fast process. As a general rule, for $\theta_{\mathrm{Y}}>20^{\circ}$, the "spreading time" $t_{\text {spr }}$ (defined as the 
time needed for a millimetre sized droplet to attain the equilibrium contact angle) is around $10 \mathrm{~ms}$ [6-8] (see an example in Figure 9). Significantly higher spreading times can be observed in two cases (i) in systems with equilibrium contact angles close to zero. In this case, instead of a drop, the liquid rapidly forms a film in which the viscous friction during further spreading is no longer negligible (Figure 4) and (ii) when wetting is assisted by the modification of the 2-d interface caused by an element contained in the liquid alloy.

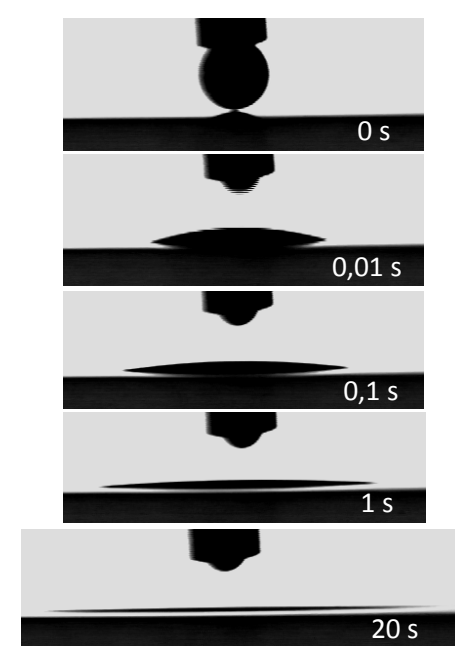

Figure 4. Spreading of a $\mathrm{CuAg}$ alloy saturated in $\mathrm{Cu}$ on monocrystalline $\mathrm{Cu}$ studied by the dispensed drop technique. The diameter of the droplet before wetting is $0.9 \mathrm{~mm}$ [9].

An example is silicon in $\mathrm{Cu}$ on silica substrates (Figure 5). The addition of 25 at $\%$ of $\mathrm{Si}$ in $\mathrm{Cu}$ leads to a decrease in the contact angle from $135^{\circ}$ for pure copper, to about $105^{\circ}$. Silicon has two effects: first it decreases the surface energy $\sigma_{L V}$ (from $1300 \mathrm{~mJ} / \mathrm{m}^{2}-1075 \mathrm{~mJ} / \mathrm{m}^{2}$ ), and second it increases the adhesion energy $W_{a}$ (from $380 \mathrm{~mJ} / \mathrm{m}^{2}-780 \mathrm{~mJ} / \mathrm{m}^{2}$ ) due to the formation of a two-dimensional layer on the silica surface with a lower $\mathrm{O} /$ metal ratio than in the bulk oxide, as in the case of the $\mathrm{Al} / \mathrm{Al}_{2} \mathrm{O}_{3}$ system. As can be easily seen from Equation (1b), both silicon effects act in the same direction, i.e., to a decreasing contact angle. The interface modification is probably the reason why the spreading time in this system is several minutes, which is orders of magnitude higher than the spreading time in systems where the wetting process takes place without modification of the interfacial chemistry.

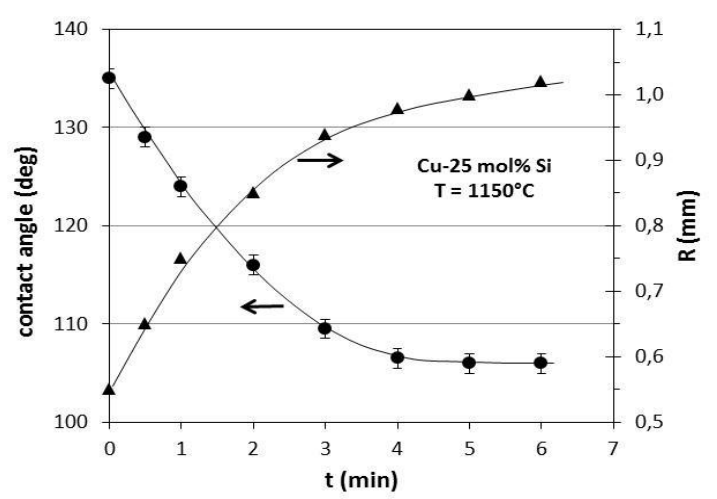

Figure 5. Contact angle and drop base radius as a function of time for a $\mathrm{Cu}-\mathrm{Si}$ alloy on silica under high vacuum. Dispensed drop technique. Results from [10]. 


\section{Reactive Wetting}

Wetting in metal/metal and metal/ceramic systems is often accompanied by reactions at the solid-liquid interface, namely simple dissolution of the solid into the liquid or formation of a 3-d layer of a new compound.

\subsection{Wetting with Formation of a New Compound at the Interface}

The thermodynamics and kinetics of reactive wetting with formation of a new compound at the interface are given by the Reaction Product Control (RPC) model which can be summarised as follows: [2]. The contact angle in such a system varies between two characteristic contact angles, the initial contact angle $\theta_{0}$, which is the contact angle on the unreacted substrate, and the final contact angle $\theta_{\mathrm{F}}$, which is the contact angle on the reaction product (Figure 6):

$$
\begin{aligned}
& \theta_{0}=\theta_{\mathrm{S}} \\
& \theta_{\mathrm{F}}=\theta_{\mathrm{P}}
\end{aligned}
$$

This is true not only when the reaction product is better wetted than the initial substrate, as in the case of $\mathrm{Si} / \mathrm{C}$ couple depicted in Figure 6, but also when the opposite situation occurs, for instance in the couples $\mathrm{Ag} / \mathrm{SiC}, \mathrm{Cu} / \mathrm{SiC}$ (see Sections 3 and 4) and $\mathrm{Au} / \mathrm{TiC}$. Pure Au does not wet TiC with a contact angle of about $130^{\circ}$, a value that is similar to that obtained for Au on carbon substrates [11] (Figure 7). Because of the strong interaction between $\mathrm{Au}$ and $\mathrm{Ti}$ a slight dissolution of $\mathrm{Ti}$ from the substrate to the liquid occurs. However, given that the solubility of $\mathrm{C}$ is much smaller than for $\mathrm{Ti}$, graphite precipitates at the surface and the measured contact angle of $130^{\circ}$ is characteristic of the reacted interface: $\mathrm{Au}$ on graphite. Since the solubility of $\mathrm{C}$ in molten $\mathrm{Ni}$ and $\mathrm{Fe}$ (but not in $\mathrm{Cu}$ ) is several orders of magnitude higher than in $\mathrm{Au}$, small additions of these elements in Au increase the solubility of $\mathrm{C}$ significantly and, thereby, prevent the formation of the graphite interface layer on the TiC substrate. As a result, the experimental results show a dramatic decrease in contact angle with a few at.\% of $\mathrm{Ni}$ or Fe without any reaction product at the interface. In this system, the action of Ni and $\mathrm{Fe}$ is to remove, by dissolution, the wetting barrier that inhibits spreading.

The spreading time $t_{s p r}$ in metal/metal and metal/ceramic reactive systems is in the range $10-10^{4} \mathrm{~s}$, i.e., several orders of magnitude higher than $t_{s p r} \approx 10^{-2} \mathrm{~s}$ observed for non-reactive metals. Therefore, in a given reactive system, $t\left(\theta_{\mathrm{F}}\right)>t\left(\theta_{0}\right)$, which implies that the spreading rate of the reactive stage is limited by the interfacial reaction itself. In [12], the RPC model was greatly improved thanks to an analytical approach used to describe spreading in systems where the growth rate of the reaction layer parallel to the interface is controlled by the chemical reaction localized at the triple line.

Note that in 1998, Saiz et al. [13] proposed an approach in which the reactive wetting is assumed to be caused mainly by adsorption, whereas spreading kinetics is controlled by the migration of a ridge formed at the solid-liquid-vapour triple line. However, detailed comparisons between predictions made by this model and experimental data did not confirm the Saiz et al. approach $[14,15]$. 

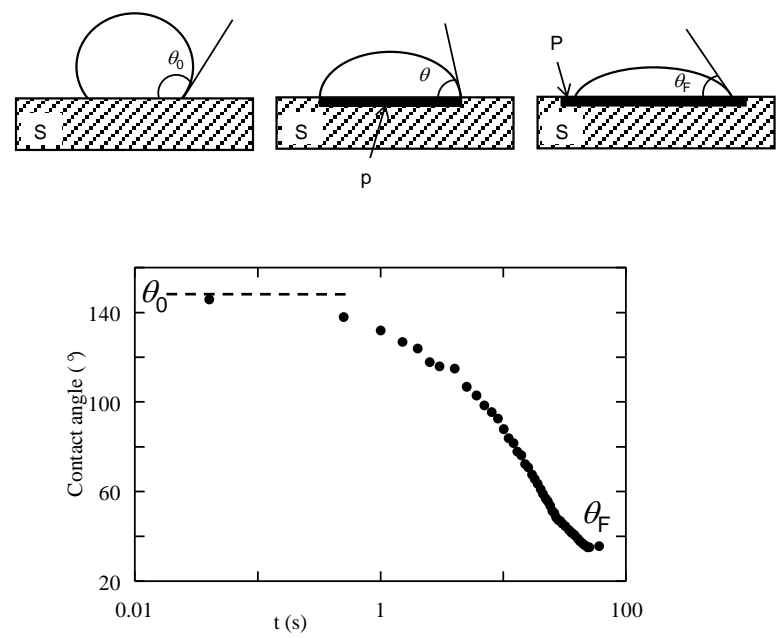

Figure 6. Top: Schematic representation of the "Reaction Product Control" model [2]. The initial contact angle $\theta_{0}$ is the contact angle on the surface of the unreacted ceramic substrate S. After a transient stage, a quasi-state configuration is established at the triple line where the advance of the liquid is hindered by the presence of a non-wettable substrate in front of the triple line. Thus, the only way to move ahead is by lateral growth of the wettable reaction product layer $\mathrm{P}$ until the macroscopic contact angle equals the equilibrium contact angle $\theta_{\mathrm{F}}$ of the liquid on the reaction product. Bottom: Contact angle vs. $\log$ for $\mathrm{Si}$ on vitreous carbon (where $\mathrm{P}=\mathrm{SiC}$ ) according to [16].
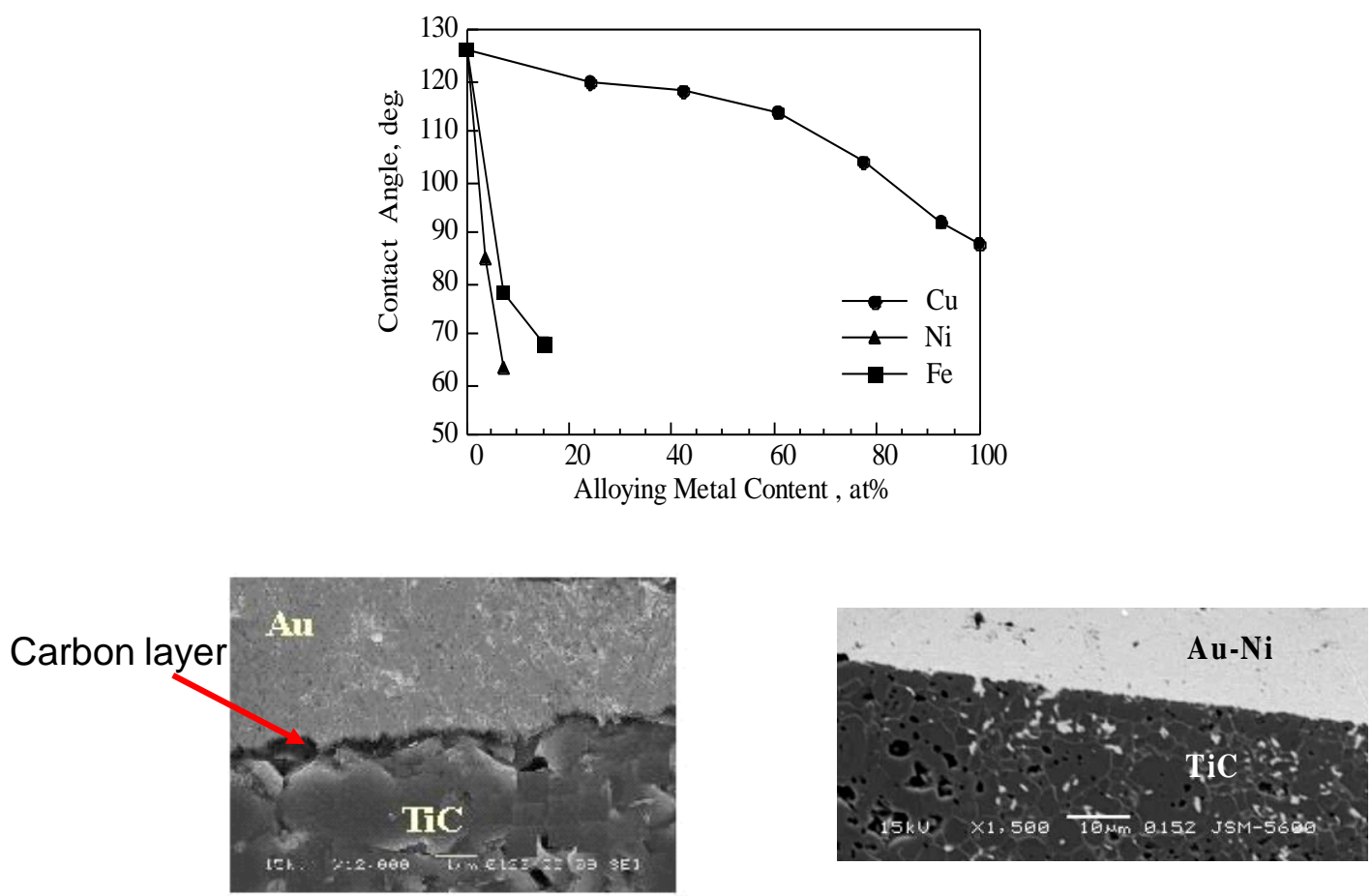

Figure 7. Top: Contact angle between $\mathrm{TiC}$ and $\mathrm{Au}$ alloys at $1150{ }^{\circ} \mathrm{C}$. Bottom: Metal/TiC interfaces for pure $\mathrm{Au}$ and an Au-Ni alloy [11]. 


\subsection{Dissolutive Wetting}

Extensive dissolution of a solid in a liquid is a phenomenon occurring in many liquid metal/solid metal systems as well as in some metal/ceramic ones, such as $\mathrm{Ni} / \mathrm{C}$ and $\mathrm{Ni} / \mathrm{SiC}$. Dissolution can reduce the observed (or visible) contact angle through two effects: first by decreasing the surface tension of the liquid, which occurs when the surface tension of the solid is much lower than that of the liquid; second by forming under the droplet, a crater such that the observed contact angle $\theta_{\text {ap }}$ is lower than the true angle $\theta_{\mathrm{F}}$ formed at the solid/liquid/vapour junction (Figure 8).

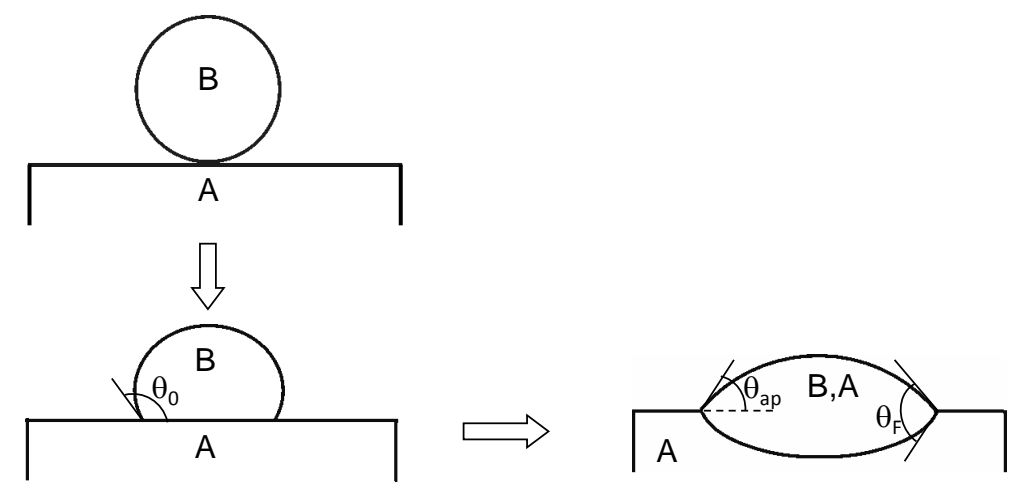

Figure 8. Dissolutive wetting: Wetting of a liquid metal B leads rapidly, within a few ms, to a first contact angle $\theta_{0}$ corresponding to the intrinsic contact angle of pure $\mathrm{B}$ in metastable equilibrium with $\mathrm{A}$. Then, the wetting process continues with the formation of a crater until saturation of B in A [8].

Protsenko et al. proposed that dissolution results in further spreading of the liquid on the substrate surface in order to maintain the capillary equilibrium at the three phase junction [8]. Accordingly, $\theta_{\mathrm{F}}$ should be the intrinsic contact angle of a B liquid saturated in A on solid A measured on an inclined solid surface. Conversely, other authors consider that this angle does not result from the equilibrium of surface energies but by diffusion of dissolved species from the interface to the liquid bulk [17]. As for the spreading time, experimental values of this quantity are higher than for non-reactive spreading, varying between seconds and hundreds of seconds, depending on the solubility of the solid in the liquid, droplet size, contact angle and temperature [8,17]. An example is given in Figure 9 for pure $\mathrm{Cu}$ on solid Si compared to copper presaturated in $\mathrm{Si}$.

A new effect of dissolution on wettability was recently highlighted by Lai et al. [18] in wetting experiments of two-phase composite $\mathrm{Cu}-\mathrm{Fe}$ substrates by molten $\mathrm{Sn}$. It was found that the curve of contact angle versus the surface fraction of composite components passes through a minimum, behaviour that cannot be interpreted by Equation (4). It was shown that the enhanced wetting observed on the composite substrate (Figure 10) can be explained by the dissolution contrast of $\mathrm{Cu}$ and $\mathrm{Fe}$ phases, leading to increasing interfacial roughness, thus providing an additional driving force for wetting. 

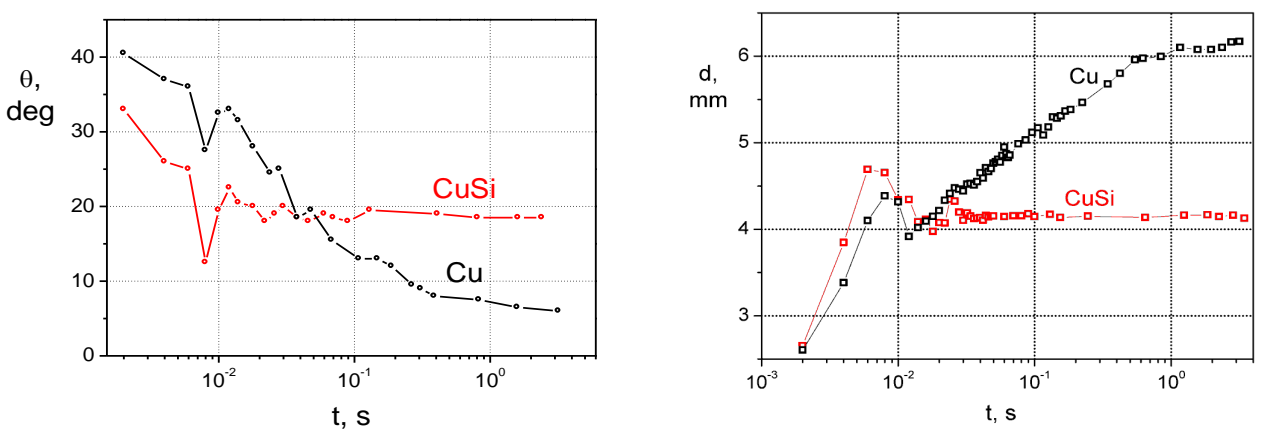

Figure 9. Visible contact angle (left) and drop base diameter (right) as a function of time plotted on a logarithmic scale for $\mathrm{Cu}$ and $\mathrm{Cu}$ presaturated in $\mathrm{Si}$ on a (001) Si surface at $1100{ }^{\circ} \mathrm{C}$. Dispensed drop technique [8].
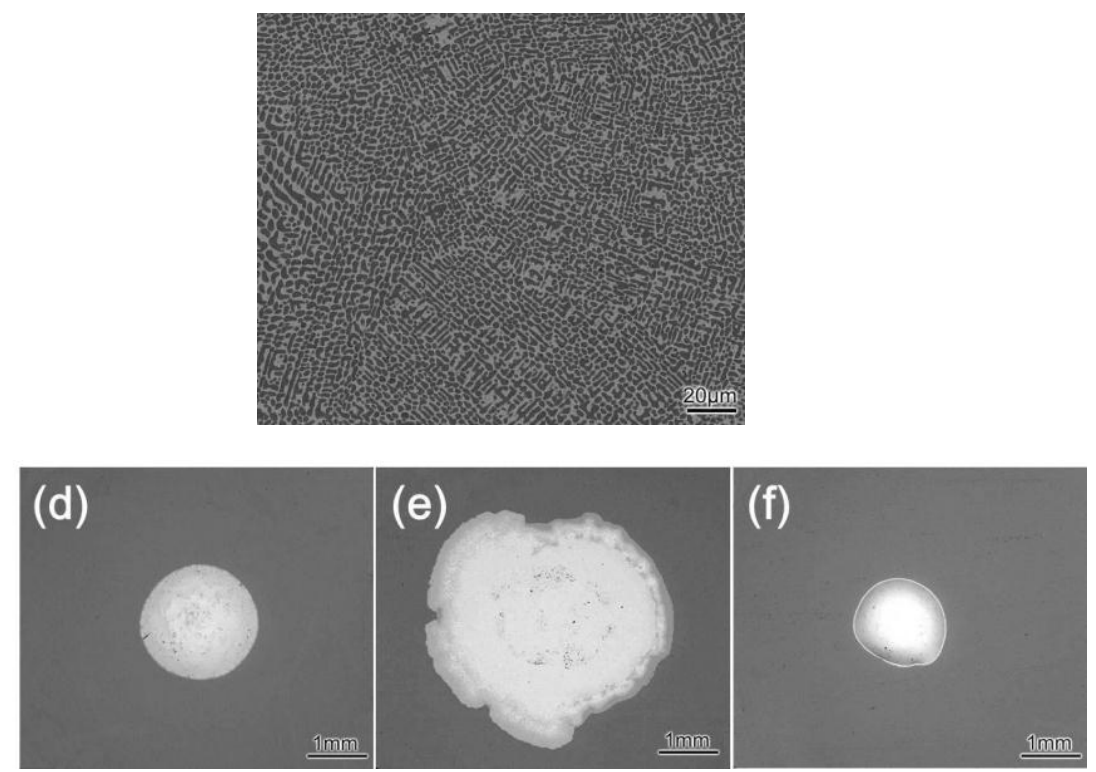

Figure 10. Top: Microstructure of a $\mathrm{Cu}-\mathrm{Fe}$ alloy with $50 \mathrm{wt} \% \mathrm{Cu}$. Iron is dark, copper is grey. Bottom: top-view of areas wetted by $\mathrm{Sn}$ on $\mathrm{Cu}, \theta=25^{\circ}(\mathbf{d}), 50 \mathrm{Cu}-50 \mathrm{Fe}, \theta=5^{\circ}$ (e) and $\mathrm{Fe} \theta=47^{\circ}$ (f) [18].

\subsection{Dissolution vs. Formation of a New Compound}

In many liquid metal-solid systems, the formation of a new compound is preceded by the dissolution of the solid in the liquid. The initial dissolution rate is high; however, once a layer of the new compound is formed at the interface, the dissolution rate decreases rapidly. An example which illustrates the two types of reactive wetting is given by results obtained by the dispensed drop technique with an $\mathrm{Au}-40$ at $\% \mathrm{Ni}$ alloy on $\mathrm{ZrB} 2$ substrates [19]. The experiments were performed at two temperatures, $980{ }^{\circ} \mathrm{C}$ and $1170{ }^{\circ} \mathrm{C}$. A nickel boride is formed at the alloy/ZrB 2 interface at $980{ }^{\circ} \mathrm{C}$ while dissolution of $\mathrm{ZrB}_{2}$ into the liquid alloy occurs only at $1170{ }^{\circ} \mathrm{C}$. Thus, by varying the temperature, it is possible to change the type of metal-ceramic reactivity by keeping the composition of the metallic phase constant. Figure 11 gives the time-dependent change of drop base diameter in an experiment at $1170{ }^{\circ} \mathrm{C}$, as well as during the subsequent cooling. Due to the metal-like character of $\mathrm{ZrB}_{2}$, the initial contact angle is low $\left(28^{\circ}\right)$ and decreases slightly to $25^{\circ}$ thanks to substrate dissolution. 
Further spreading was observed when the temperature decreased to values where formation of the new compound $\left(\mathrm{Ni}_{2} \mathrm{~B}\right)$ becomes possible.

The micrograph of the region near the triple line (Figure 11) shows the position of the triple line before cooling, separating the dissolution cavity formed at $1170{ }^{\circ} \mathrm{C}$ from the interface zone produced at lower temperature. The reaction product layer covering the interface, a few microns thick, can also be distinguished. From these observations it is easy to understand the unusual result depicted in Figure 11, namely that a decrease in temperature improves wettability.
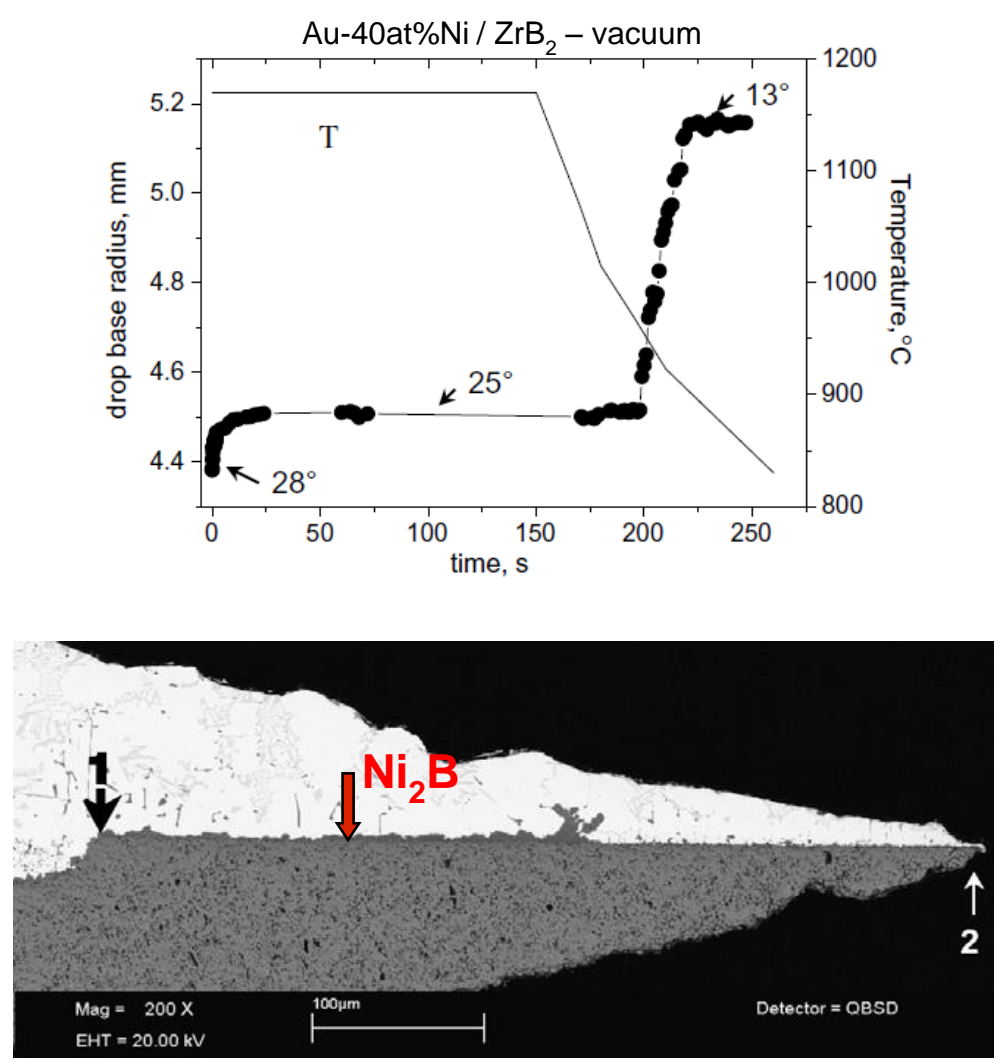

Figure 11. $\mathrm{Au}-40$ at $\% \mathrm{Ni} / \mathrm{ZrB}_{2}$ system. Top: Drop base radius and temperature as a function of time. The numbers on the drop base radius curve represent the corresponding values of the contact angle. Bottom: Micrograph of the interface close to the triple line formed during cooling. 1 and 2 indicate the positions of the triple line before and after cooling [19].

In the previous example, the formation of a new compound at the interface leads to a net, but limited, improvement in wetting. This is because both the initial solid $\left(\mathrm{ZrB}_{2}\right)$ and the reaction product (nickel boride) are metallic in character and thus wettable by liquid metals. A much more pronounced improvement is observed in the example depicted in Figure 12 for two Ni-Si alloys on graphite at $1270{ }^{\circ} \mathrm{C}$ [20]. For the Ni-21 at\% Si alloy, only a limited dissolution of graphite in the liquid takes place. The steady contact angle attained a few minutes after melting is close to $120^{\circ}$. A completely different behaviour is exhibited by a $\mathrm{Ni}-47$ at $\% \mathrm{Si}$ alloy, leading to the formation of wettable $\mathrm{SiC}$ at the interface. The alloy was shown to wet the graphite with a steady contact angle of $40^{\circ}$. As will be discussed in the following section, this wetting results in liquid alloy infiltrating the porous graphite. 

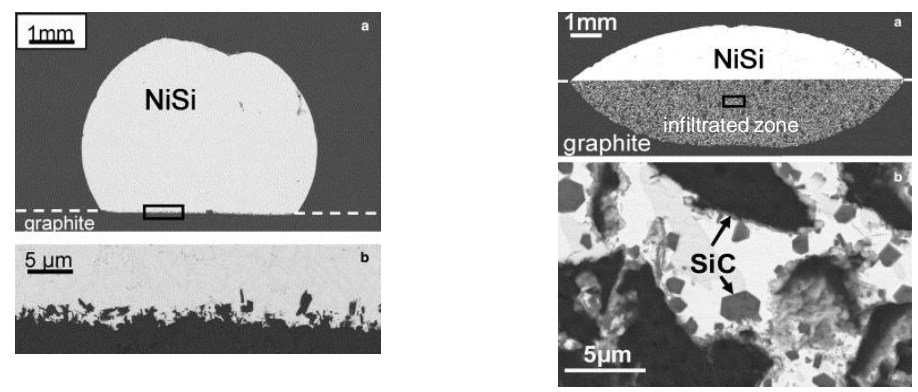

Figure 12. Micrographs of two NiSi alloy/graphite sectioned samples, Left: $\mathrm{Ni}-21$ at\% Si, (a) general view; (b) alloy/carbon interface. Only a limited dissolution of graphite is observed. Right: Ni-47 at\% Si, (a) general view; (b) an area of the infiltrated zone [20]. $T=1270{ }^{\circ} \mathrm{C}$.

\section{Application in Processing of Materials}

\subsection{Wetting in Infiltration}

Metal/ceramic composites are often processed by infiltration of porous ceramics by liquid metals $[21,22]$. Under the temperature and atmosphere conditions normally used in practice, liquid metals $(\mathrm{Cu}, \mathrm{Al}$, etc.) do not wet ionocovalent ceramics such as alumina, silicon carbide or graphite and, for this reason, infiltration is achieved by applying a sufficiently high pressure $P_{0}$ (Figure 13a) to overcome the capillary pressure

$$
P_{\mathrm{C}}=-\left(2 \sigma_{L V} / r_{e f f}\right) \cos \theta
$$

where $r_{\text {eff }}$ is an effective pore radius characteristic of the preform and $\theta$ the contact angle on pore walls. In numerous studies published since the 1990s (see for instance [23,24]), it has been found that the infiltration distance $h$ increases parabolically with both time $\mathrm{t}$ and excess pressure $\Delta P=P_{0}-P_{\mathrm{C}}$. This agrees with the following equation established by Washburn [25] assuming that infiltration is limited by viscous friction:

$$
h^{2}=r_{e f f}^{2} \frac{\Delta P}{4 \eta} t
$$

For wetting liquids (Figure 13b) pressureless infiltration becomes possible, described by Equation (7) which, introducing the expression of capillary pressure $P_{\mathrm{C}}$ and taking $P_{0}=0$, becomes:

$$
h^{2}=r_{e f f} \frac{\sigma_{L V} \cos \theta}{2 \eta} t
$$

According to Equations (6) and (8), pore infiltration is possible if the equilibrium contact angle $\theta$ is lower than a threshold contact angle $\theta^{*}=90^{\circ}$. This value is only valid for strictly parallel pore walls having smooth surfaces. For real porous media, the inequality $\theta<90^{\circ}$ for a liquid with an intrinsic contact angle $\theta$ does not guarantee that infiltration will occur. In the first place, pore walls are rough and if $\theta$ is too close to the threshold contact angle, this roughness can hinder infiltration. Secondly, the pore walls are never parallel. Consequently, if during infiltration the liquid-vapour surface area increases, as in the $\mathrm{V}$-shaped pore depicted in Figure $14, \theta^{*}$ is no longer equal to $90^{\circ}$ but to $90^{\circ}-\varphi$. 
In practice, contact angles as low as $60^{\circ}$ seem to be necessary in order to ensure spontaneous infiltration [26,27].

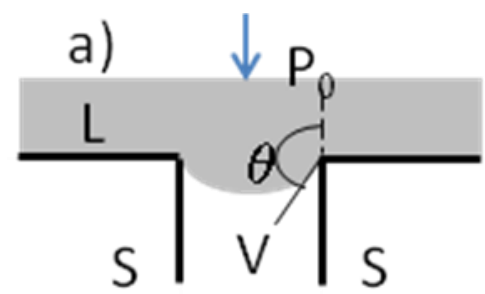

b)

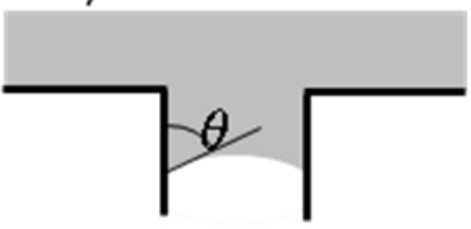

c)

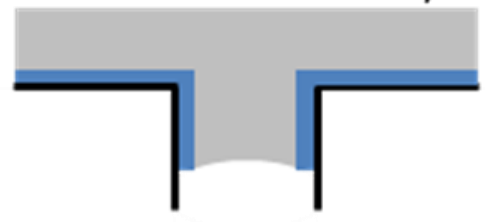

d)

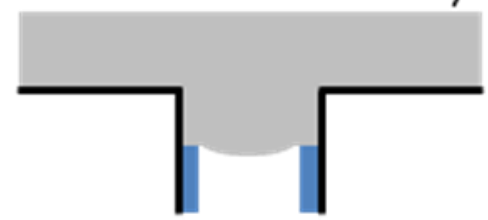

Figure 13. Schematic presentation of pore infiltration by a liquid in non-reactive $(\mathbf{a}, \mathbf{b})$ and reactive (c,d) systems. In case (c), the infiltration of a non-wettable solid $S$ is assisted by the formation of a wettable reaction product layer (example: Si/porous graphite). In case (d), the infiltration of a wettable solid is hindered by the presence of a non-wettable layer covering the pore walls (example: $\mathrm{Si} /$ oxidised porous $\mathrm{Si}_{3} \mathrm{~N}_{4}$ ).

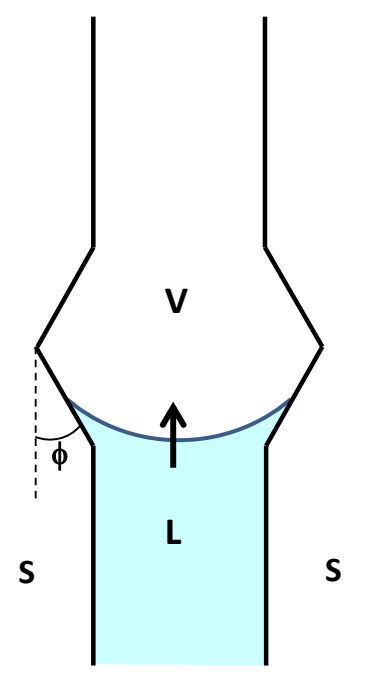

Figure 14. Infiltration in a pore locally exhibiting an increase in pore area perpendicular to the infiltration direction.

An example of spontaneous infiltration is silicon in porous carbon performs. Liquid silicon is known to wet carbon and it can therefore spontaneously infiltrate a carbon preform. Infiltrated Si reacts with carbon to form SiC. Reactive infiltration is used to process the so-called "reaction-bonded silicon carbide" or SiC composites [28,29].

For a long time, infiltration of $\mathrm{Si}$ and silicon rich alloys into porous carbon has been described as consisting of rapid, non-reactive, infiltration obeying Washburn's equation followed by the reaction between $\mathrm{Si}$ and $\mathrm{C}$ to form $\mathrm{SiC}$ [30-32]. Three experimental facts disagree with this model: (i) Infiltration of porous graphite by $\mathrm{Si}$ and $\mathrm{NiSi}$ alloys rich in silicon does not show a parabolic trend 
as predicted by Wasbhurn's equation, but is linear with time (Figure 15) (ii) Si does not wet unreacted carbon substrates as shown by the large obtuse $\theta_{0}$ value in the curve of Figure 6 . This is also indicated by the results obtained for the $\mathrm{Ni}-\mathrm{Si} / \mathrm{C}$ couple presented in the previous section and depicted in Figure 12. These results strongly suggest that silicon carbide formation at the $\mathrm{Si} / \mathrm{C}$ interface is a necessary condition for wetting and infiltration. (iii) Further evidence is given by the experimental values of the infiltration rate $\mathrm{dh} / \mathrm{dt}$ which, in the case of pure $\mathrm{Si}$, is $5-10 \mu \mathrm{m} / \mathrm{s}$, nearly equal to the spreading rate $\mathrm{dR} / \mathrm{dt}$ [33] but several orders of magnitude lower than the values predicted by Washburn's equation which are in the $\mathrm{mm} / \mathrm{s}$ range. It is concluded that the infiltration rate in this system is controlled by the rate of growth of $\mathrm{SiC}$ parallel to the pore walls at the infiltration front (Figure 13c).

a
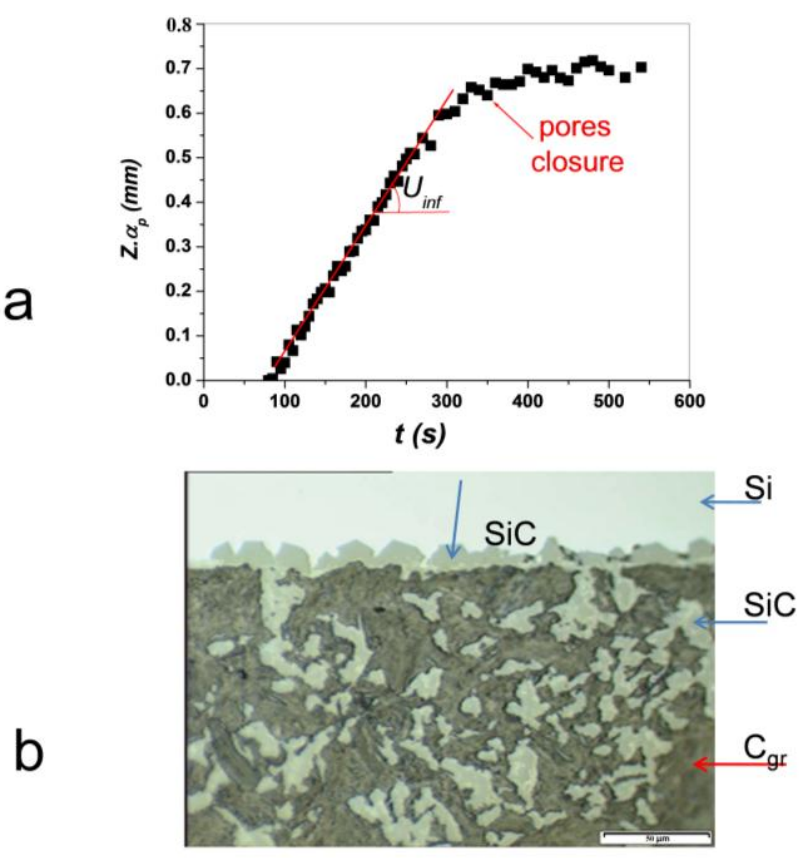

Figure 15. Infiltration of porous graphite (pore volume fraction $\alpha_{p}=0.15$ ) by molten silicon. (a) Variation with time of the quantity $Z \alpha_{p}$ where $\mathrm{Z}$ is the infiltration distance $(\mathrm{Z}=\mathrm{h}$ in Equations (7) and (8)). (b) Reacted interface and infiltrated zone $[33,34]$.

Another example of spontaneous infiltration is infiltration of silicon in porous silicon nitride coatings of silica crucibles used in the crystallisation of photovoltaic (PV) quality silicon. When Si-PV is processed by liquid state routes, solidified $\mathrm{Si}$ adheres to the crucible walls leading to thermo-mechanical stress and resulting in loss of Si electrical performance and crucible deterioration and even destruction.

In order to avoid adherence, large non-wetting contact angles are needed to obtain the "composite interface" configuration shown in Figure 3a. However, as a general rule the contact angles of silicon on ceramic materials are close to or lower than $90^{\circ}$ [35], far below the values needed in order to obtain non-adherence. The only exception is hc-BN, a ceramic for which non-wetting behaviour of $\mathrm{Si}$ is observed. However, for this ceramic, boron contamination leads to overdoping of silicon (hundreds of ppm) incompatible with applications in PV-silicon [36]. In the absence of a satisfactory dense material crucible, photovoltaic silicon ingots are currently grown in $\mathrm{SiO}_{2}$ crucibles coated with a 
silicon nitride powder, which acts as an interface releasing agent between silicon and the crucible. The phenomena occurring at the liquid $\mathrm{Si}$ /porous $\mathrm{Si}_{3} \mathrm{~N}_{4}$ interface were studied and modelled in [37]. The coating is processed starting from a silicon nitride submicronic powder where all $\mathrm{Si}_{3} \mathrm{~N}_{4}$ particles are covered by a silica layer a few nanometres thick. Figure 16 presents the results obtained in a sessile drop experiment performed under argon flow for uncoated dense $\mathrm{Si}_{3} \mathrm{~N}_{4}$ used as a reference substrate. In order to simulate the process conditions, the substrate was preoxidised in air. When a droplet of silicon is placed on the surface of such a silicon nitride substrate the contact angle varies with time between two values: an initial contact angle close to 90 degrees which is the contact angle on the silica skin (the contact angle on the surface of bulk silica is indeed close to $90^{\circ}$ ), and a final contact angle of about $45^{\circ}$ attained after about $500 \mathrm{~s}$, which is the equilibrium contact angle on a clean, deoxidised silicon nitride surface. Therefore, the wetting kinetics in this system is controlled by the removal of the oxide film occurring by the dissolution of silica in molten silicon followed by the diffusion of dissolved oxygen towards the Si free surface where oxygen is evacuated in the form of gaseous silicon monoxide $\mathrm{SiO}$. The overall reaction is:

$$
\mathrm{SiO}_{2}(\mathrm{~S})+\mathrm{Si}(\mathrm{L}) \rightarrow 2 \mathrm{SiO}(\mathrm{G})
$$

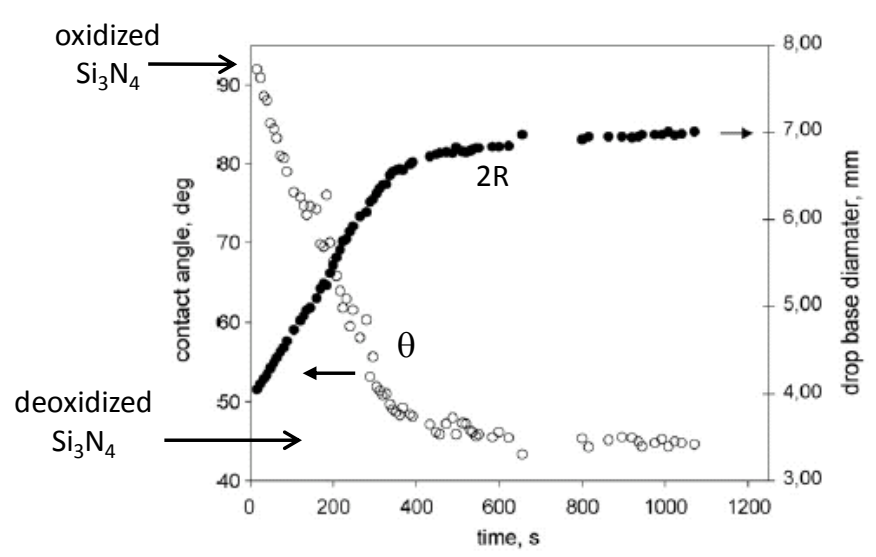

Figure 16. Wetting curves (contact angle and drop base diameter $2 \mathrm{R} v s$. time) for liquid $\mathrm{Si}$ on $\mathrm{Si}_{3} \mathrm{~N}_{4}$ covered by a silica layer a few nm thick. $T=1430{ }^{\circ} \mathrm{C}$, in $\operatorname{Ar}$ [36].

As for infiltration, since the contact angle of silicon on oxidised silicon nitride is close to $90^{\circ}$, molten Si does not infiltrate the porous coating as long as the pore walls are covered by an oxide film (Figure 13d). The infiltration rate is in this case equal to the dissolution rate of oxide film in silicon at the infiltration front [37]. The resulting rates $\mathrm{d} h / \mathrm{d} t$ are small enough to avoid the detrimental phenomenon of sticking during a melting/crystallisation cycle of Si-PV.

\subsection{Wetting in Brazing: Effect of Interfacial Reactions}

When a small piece of a metal such as $\mathrm{Cu}$ or $\mathrm{Ni}$ is placed on silicon carbide, a strong reaction between the metal and silicon carbide takes place [38]. The reaction consists of SiC dissolution in the metal while the excess carbon forms graphite precipitates close to the interface:

$$
\mathrm{SiC}(\mathrm{S}) \rightarrow[\mathrm{Si}]+\mathrm{C}_{\mathrm{gr}}
$$


where the parenthesis means silicon dissolved in the metal. While liquid metals wet clean SiC surfaces, they do not wet graphite. Therefore, this reaction inhibits wetting and additionally leads to the formation of brittle graphite particles that are detrimental to mechanical properties. To avoid these effects, metal-silicon alloys are used instead of pure metal. For a given system, the silicon concentration is chosen such that the formation of graphite precipitates is suppressed. For instance, a non-reactive Si-Pr alloy/silicon carbide interface is obtained (Figure 17) together with good wetting (the contact angle in this system is around 40 degrees) [39]. These findings are the basis of new alloys developed in Grenoble for joining SiC and other carbonaceous materials by brazing.

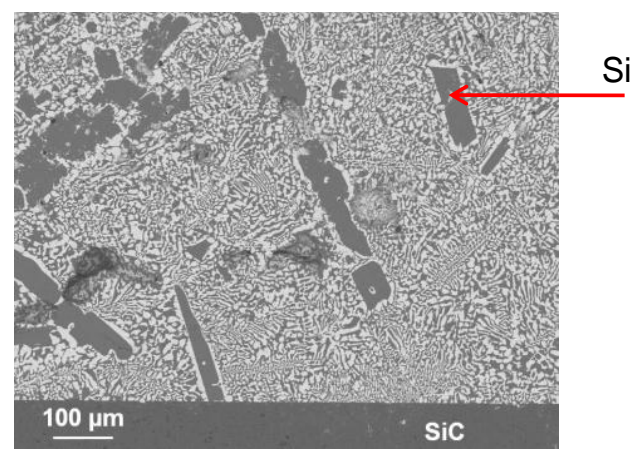

Figure 17. Cross-section of a Si-Pr alloy on sintered $\alpha$-SiC obtained after $15 \mathrm{~min}$ at $1250{ }^{\circ} \mathrm{C}$ in high vacuum. The primary Si crystals are surrounded by the eutectic PrSi2-Si. The reactivity is negligible and the interface is mechanically strong [39].

In the above example, the interfacial reaction is detrimental for wetting and brazing. In many other situations, the interfacial reaction can promote wetting and brazeability. This is the case depicted in Figure 6 for the Si/carbon system where $\mathrm{SiC}$ formed at the interface is better wetted than the initial graphite. Another example is wetting of alumina by $\mathrm{CuAg}$ alloys containing a few per cent of $\mathrm{Ti}$. The effect of $\mathrm{Ti}$ on wetting is illustrated by the sessile drop experiment, depicted in Figure 18, in which a $\mathrm{CuAg}-1.75 \mathrm{wt} \% \mathrm{Ti}$ alloy was processed in situ, by placing a small quantity of $\mathrm{Ti}$ on top of a piece of $\mathrm{AgCu}$ on an alumina substrate [40].

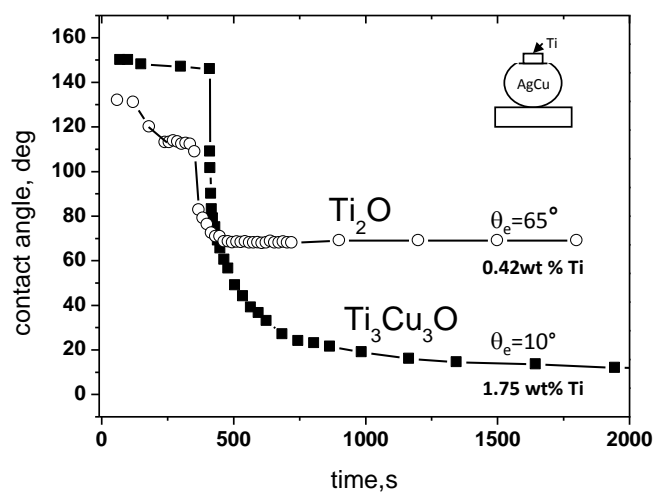

Figure 18. Contact angle as a function of time for two $\mathrm{CuAg}$-Ti droplets of different composition processed in situ on monocrystalline alumina in $\mathrm{He}$ at $900{ }^{\circ} \mathrm{C}$. According to [40]. 
The large, non-wetting, contact angle observed at melting, which is typical of a non-reactive noble metal on an oxide, is the contact angle of $\mathrm{CuAg}$ alloy on alumina. This angle remains constant for several minutes, the time needed for Ti to dissolve in the liquid and reach the metal-oxide interface by diffusion. Afterwards, the contact angle decreases rapidly towards a value close to $10^{\circ}$, which corresponds to excellent wetting.

The micrograph in Figure 19 presents the interface formed between the alloy and alumina at the end of the wetting experiment. The reactive interface is composed of two layers. The layer formed in contact with the liquid alloy, was identified as the $\mathrm{Cu}_{3} \mathrm{Ti}_{3} \mathrm{O}$ compound. The low final contact angle observed in this system is precisely due to the metallic character of this compound. A thin, submicronic layer is also formed in contact with alumina and identified as the $\operatorname{Ti}_{2} \mathrm{O}$ suboxide. By decreasing the Ti concentration in the alloy from 1.75-0.42 wt\%, only the Ti suboxide was formed at the interface and, as a consequence, a very significant increase in the equilibrium contact angle was observed. Even higher contact angles can be observed with further reduction in Ti concentration or, more generally, of titanium activity in the alloy, which is in reality the relevant thermodynamic quantity involved in the interfacial reactivity. Information obtained by the above sessile drop experiments provided useful information concerning brazing of alumina by $\mathrm{CuAgTi}$ alloys [41].

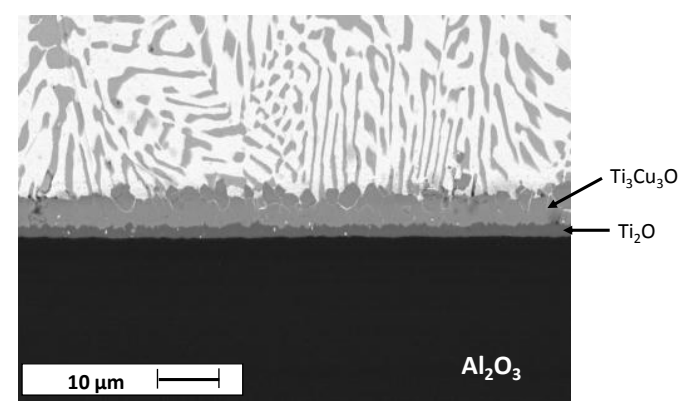

Figure 19. Cross-section of a CuAg-3 at $\% \mathrm{Ti} / \mathrm{Al}_{2} \mathrm{O}_{3}$ interface, after $30 \mathrm{~min}$ at $900{ }^{\circ} \mathrm{C}$ in He. According to [40].

When alumina (or another ceramic) is brazed to a metallic partner Me, the interactions between Me and the brazing alloy can affect the joint microstructure and the interfacial chemistry. Indeed, as the diffusion time in a liquid gap of 100 microns is only a few seconds, Me dissolves in the liquid braze and attains rapidly its equilibrium concentration. For instance, when one of the alumina pieces is replaced by a copper-nickel plate, the dissolution of $\mathrm{Ni}$ and $\mathrm{Cu}$ from the plate in the liquid braze leads to a dramatic change in joint microstructure and also a net change in reactivity at the alumina/braze interface (Figure 20) consisting of a decrease in the thickness of the interfacial reaction layer by one order of magnitude (from $\sim 2 \mu \mathrm{m}$ to $\sim 200 \mathrm{~nm}$ ). Moreover, instead of the wettable $\mathrm{Cu}_{3} \mathrm{Ti}_{3} \mathrm{O}$ compound formed at the interfaces in the alumina to alumina joint, high oxidation-level Ti oxides are formed in the case of $\mathrm{CuNi} /$ alumina joint, resulting in a very significant increase in contact angle towards $90^{\circ}$ and ultimately in the mechanical weakening of the interface and of the actual joint [42]. From these results, it appears that when ceramics are brazed to metallic parts, allowance must be made not just for the well-known problem of thermo-mechanical compatibility between these two types of solid but also for the interactions between the metallic part and the braze that can affect wetting as well as the joint composition and microstructure. 
(a)

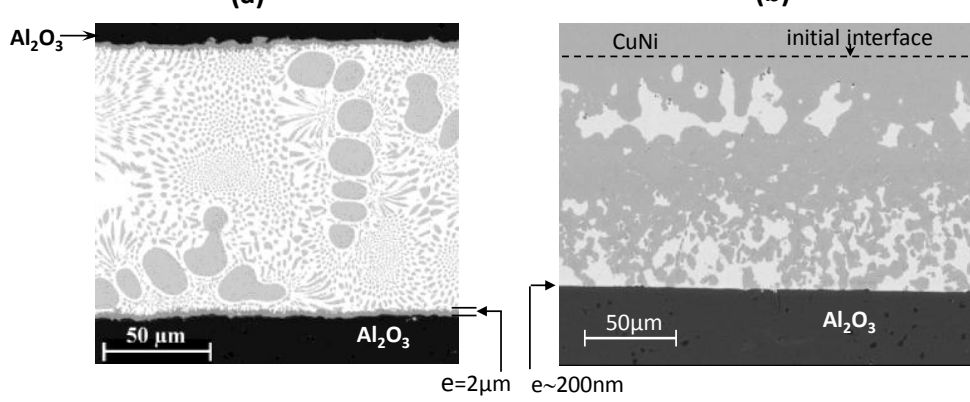

Figure 20. Cross-sections of (a) alumina to alumina and (b) alumina to CuNi plates. Assemblies brazed by a $\mathrm{CuAg}$-Ti alloy $\left(900{ }^{\circ} \mathrm{C}, 15 \mathrm{~min}\right) . e$ denotes here the thickness of the interfacial reaction product. According to [42].

\section{Conclusions and Perspectives}

During the last 15 years, a large number of studies have been published on the fundamentals of reactive wetting. Some of them have focused on the dissolutive wetting studied using simple model systems. Although these studies have contributed significantly to improving our knowledge of dissolutive wetting, more work is needed to clarify points where diverging opinions persist, especially on the driving force of this type of wetting.

For reactive systems, where wetting is accompanied by the formation of a layer of a new compound at the interface, a first version of the Reaction Product Control (RCP) model was proposed in [43]. The model was greatly improved thanks to the analytical approach proposed in [12] for the case where spreading kinetics is limited by the local chemical process at the triple line. This approach completes the previously published, similar study by Mortensen et al. on diffusion controlled reactive spreading [44].

The RCP model has been applied with success in the analysis of experimental data obtained with various ceramic substrates, namely the different types of carbon [15,16], oxides [40], nitrides [45] or borides [19]. A main assumption in the model is that the new compound growth process takes place inside a zone of submicronic size localised around the solid-liquid-vapour junction, where the reactive element contained in the liquid has direct access to the solid substrate. This seems to be a reasonable assumption when experiments are performed in neutral gas or in vacuum but at low or moderate temperatures. However, experiments performed for the $\mathrm{Si} /$ graphite couple in high vacuum at $1430{ }^{\circ} \mathrm{C}$, showed different wetting kinetics than in neutral gas [33]. In high vacuum, the transport of a reactive solute through the vapour can modify the surface chemistry of the substrate in front of the triple line and thus enhance spreading. A similar effect is expected to occur under an inert gas but at higher temperatures. A general description of reactive wetting taking into account both the localised and delocalised reaction is still lacking.

In this review, several examples have been given showing how simple wetting experiments can provide very useful information on the basic mechanisms involved in materials processing by infiltration or in joining similar or dissimilar materials by brazing alloys.

As for the experimental methods used in wettability studies, great improvements are expected to be made in the near future, including the development of new devices where sessile drop experiments can 
be coupled in the same chamber with high temperature surface analysis techniques (by Auger or XPS spectroscopy). The execution of surface analysis at high temperatures is a difficult but very exciting objective.

\section{Conflicts of Interest}

The author declares no conflict of interest.

\section{References}

1. Eustathopoulos, N.; Sobczak, N.; Passerone, A.; Nogi, K. Measurement of contact angle and work of adhesion at high temperature. J. Mater. Sci. 2005, 40, 2271-2280.

2. Eustathopoulos, N.; Drevet, B.; Nicholas, M.G. Wettability at High Temperatures; Pergamon: Oxford, UK, 1999; Volume 3.

3. Kumar, G.; Prabhu, K.N. Review of non-reactive and reactive wetting of liquids on surfaces. Adv. Colloid Interface Sci. 2007, 133, 61-89.

4. Eustathopoulos, N.; Drevet, B.; Muolo, M.L. The oxygen-wetting transition in metal/oxide systems. Mater. Sci. Eng. A 2001, 300, 34-40.

5. Battezzati, L.; Greer, L.A. The viscosity of liquid metals and alloys. Acta Metall. 1989, 37, 1791-1802.

6. Saiz, E.; Tomsia, A.P. Atomic dynamics and Marangoni films during liquid-metal spreading. Nat. Mater. 2004, 3, 903-909.

7. Saiz, E.; Tomsia, A.P.; Rauch, N.; Scheu, C.; Ruehle, M.; Benhassine, M.; Seveno, D.; de Coninck, J.; Lopez-Esteban, S. Nonreactive spreading at high temperature: Molten metals and oxides on molybdenum. Phys. Rev. E 2007, 76, 041602-041615.

8. Protsenko, P.; Garandet, J.-P.; Voytovych, R.; Eustathopoulos, N. Thermodynamics and kinetics of dissolutive wetting of Si by liquid Cu. Acta Mater. 2010, 28, 6565-6574.

9. Kozlova, O.; Voytovych, R.; Protsenko, P.; Eustathopoulos, N. Non-reactive versus dissolutive wetting of Ag-Cu alloys on Cu substrates. J. Mater. Sci. 2010, 45, 2099-2105.

10. Rado, C. Contribution à l'étude du mouillage et de l'adhésion thermodynamique des métaux et alliages sur le carbure de silicium. Ph.D. Thesis, Grenoble-INP, Grenoble, France, 1997.

11. Frage, N.; Froumin, N.; Dariel, M.P. Wetting of TiC by non-reactive liquid metals. Acta Mater. 2002, 50, 237-245.

12. Dezellus, O.; Hodaj, F.; Eustathopoulos, N. Progress in modeling of chemical-reaction limited wetting. J. Eur. Ceram. Soc. 2003, 23, 2797-2803.

13. Saiz, E.; Tomsia, A.P.; Cannon, R.M. Ridging effects on wetting and spreading of liquids on solids. Acta Mater. 1998, 46, 2349-2361.

14. Eustathopoulos, N. Progress in understanding and modelling reactive wetting of metals on ceramics. Curr. Opin. Solid State Mater. Sci. 2005, 9, 152-160.

15. Bougiouri, V.; Voytovych, R.; Dezellus, O.; Eustathopoulos, N. Wetting and reactivity in Ni-Si/C system: Experiments versus model predictions. J. Mater. Sci. 2007, 42, 2016-2023.

16. Dezellus, O.; Jacques, S.; Hodaj, F.; Eustathopoulos, N. Wetting and infiltration of carbon by liquid silicon. J. Mater. Sci. 2005, 40, 2307-2311. 
17. Yin, L.; Murray, B.T.; Singler, T.J. Dissolutive wetting in the Bi-Sn system. Acta Mater. 2006, $54,3561-3574$.

18. Lai, Q.Q.; Zhang, L.; Eustathopoulos, N. Enhanced wetting of dual-phase metallic solids by liquid metals: A new effect of interfacial reaction. Acta Mater. 2013, 61, 4127-4134.

19. Voytovych, R.; Koltsov, A.; Hodaj, F.; Eustathopoulos, N. Reactive vs. non-reactive wetting of $\mathrm{ZrB}_{2}$ by azeotropic Au-Ni. Acta Mater. 2007, 55, 6316-6321.

20. Bougiouri, V.; Voytovych, R.; Rojo-Calderon, N.; Narciso, J.; Eustathopoulos, N. The role of the chemical reaction in the infiltration of porous carbon by NiSi alloys. Scr. Mater. 2006, 54, 1875-1878.

21. Evans, A.; SanMarchi, C.; Mortensen, A. Metal Matrix Composites in Industry: An Introduction and a Survey; Kluwer Academic Publishers: Dordrecht, NL, USA, 2003.

22. Mortensen, A. Melt infiltration of metal matrix composites. In Comprenhensive Composite Materials; Kelly, A., Zweben, C., Eds.; Pergamon: Oxford, UK, 2000; Volume 3, pp. 521-554.

23. Michaud, V.J.; Compton, L.M.; Mortensen, A. Capillarity in isothermal infiltration of alumina fiber preforms with aluminum. Metall. Mater. Trans. A 1994, 25A, 2145-2152.

24. Alonso, A.; Pamies, A.; Narciso, J.; Garcia-Cordovilla, C.; Louis, E. Evaluation of the wettability of liquid aluminum with ceramic particulates $\left(\mathrm{SiC}, \mathrm{TiC}, \mathrm{Al}_{2} \mathrm{O}_{3}\right)$ by means of pressure infiltration. Metall. Trans. A 1993, 24A, 1423-1432.

25. Washburn, E.W. The dynamics of capillary flow. Phys. Rev. 1921, 17, 273-283.

26. Trumble, K.P. Spontaneous infiltration of non-cylindrical porosity: Close-packed spheres. Acta Mater. 1998, 46, 2363-2367.

27. Kaptay, G.; Barczy, T. On the asymmetrical dependence of the threshold pressure of infiltration on the wettability of the porous solid by the infiltrating liquid. J. Mater. Sci. 2005, 40, 2531-2535.

28. Ness, J.N.; Page, T.F. Microstructural evolution in reaction-bonded silicon carbide. J. Mater. Sci. 1986, 21, 1377-1397.

29. Wang, Y.; Tan, S.; Jiang, D. The effect of porous carbon preform and the infiltration process on the properties of reaction-formed SiC. Carbon 2004, 42, 1833-1839.

30. Einset, E.O. Capillary infiltration rates into porous media with applications to Silcomp processing. J. Am. Ceram. Soc. 1996, 79, 333-338.

31. Sangsuwan, P.; Tewari, S.N.; Gatika, J.E.; Singh, M.; Dickerson, R. Reactive infiltration of silicon melt through microporous amorphous carbon performs. Metall. Mater. Trans. B 1999, 30B, 933-944.

32. Kumar, S.; Kumar, A.; Devi, R.; Shukla, A.; Gupta, A.K. Capillary infiltration studies of liquids into 3D-stitched C-C preforms Part B: Kinetics of silicon infiltration. J. Eur. Ceram. Soc. 2009, 29, 2651-2657.

33. Israel, R.; Voytovych, R.; Protsenko, P.; Drevet, B.; Camel, D.; Eustathopoulos, N. Capillary interactions between molten silicon and porous graphite. J. Mater. Sci. 2010, 45, 2210-2217.

34. Israel, R. Etude des interactions entre silicium liquid et graphite pour l'application à l'elaboration du silicium photovoltaique. Ph.D. Thesis, Grenoble-INP, Grenoble, France, 2009.

35. Drevet, B.; Eustathopoulos, N. Wetting of ceramics by molten silicon and silicon alloys: A review. J. Mater. Sci. 2012, 47, 8247-8260. 
36. Drevet, B.; Voytovych, R.; Israel, R.; Eustathopoulos, N. Wetting and adhesion of Si on $\mathrm{Si}_{3} \mathrm{~N}_{4}$ and BN substrates. J. Eur. Ceram. Soc. 2009, 29, 2363-2367.

37. Huguet, C.; Deschamps, C.; Voytovych, R.; Drevet, B.; Camel, D.; Eustathopoulos, N. Initial stages of silicon-crucible interactions in crystallisation of solar grade silicon: Kinetics of coating infiltration. Acta Mater. 2014, 76, 151-167.

38. Rado, C.; Drevet, B.; Eustathopoulos, N. The role of compound formation in reactive wetting: The $\mathrm{Cu} / \mathrm{SiC}$ system. Acta Mater. 2000, 48, 4483-4491.

39. Koltsov, A.; Hodaj, F.; Eustathopoulos, N. Brazing of AlN to SiC by a $\mathrm{Pr}$ silicide: Physicochemical aspects. Mater. Sci. Eng. A 2008, 495, 259-264.

40. Voytovych, R.; Robaut, F.; Eustathopoulos, N. The relation between wetting and interfacial chemistry in the CuAgTi/alumina system. Acta Mater. 2006, 54, 2205-2214.

41. Kozlova, O.; Braccini, M.; Voytovych, R.; Eustathopoulos, N.; Martinetti, P.; Devismes, M.-F. Brazing copper to alumina using reactive CuAgTi alloys. Acta Mater. 2010, 58, 1252-1260.

42. Valette, C.; Devismes, M.-F.; Voytovych, R.; Eustathopoulos, N. Interfacial reactions in alumina/CuAgTi braze/CuNi system. Scr. Mater. 2005, 52, 1-6.

43. Landry, K.; Eustathopolos, N. Dynamics of wetting in reactive metal/ceramic systems: Linear spreading. Acta Mater. 1996, 44, 3923-3932.

44. Mortensen, A.; Drevet, B.; Eustathopoulos, N. Kinetics of diffusion-limited spreading of sessile drops in reactive wetting. Scr. Mater. 1997, 36, 645-651.

45. Koltsov, A.; Hodaj, F.; Eustathopoulos, N.; Dezellus, A.; Plaindoux, P. Wetting and interfacial reactivity in Ag-Zr/sintered AlN system. Scr. Mater. 2003, 48, 351-357.

(C) 2015 by the authors; licensee MDPI, Basel, Switzerland. This article is an open access article distributed under the terms and conditions of the Creative Commons Attribution license (http://creativecommons.org/licenses/by/4.0/). 